\title{
OVERVIEW OF OPEN SOURCE SOFTWARE FOR CLOSE RANGE PHOTOGRAMMETRY
}

\author{
G. Vacca \\ DICAAR, Dept. of Civil-Environmental Engineering and Architecture, Cagliari, Italy - vaccag@unica.it
}

\author{
Commission IV, WG IV/4
}

KEY WORDS: SfM, close range photogrammetry, open source

\begin{abstract}
:
In the photogrammetric process of the 3D reconstruction of an object or a building, multi-image orientation is one of the most important tasks that often include simultaneous camera calibration. The accuracy of image orientation and camera calibration significantly affects the quality and accuracy of all subsequent photogrammetric processes, such as determining the spatial coordinates of individual points or 3D modeling. In the context of artificial vision, the full-field analysis procedure is used, which leads to the so-called Strcture from Motion ( $\mathrm{SfM}$ ), which includes the simultaneous determination of the camera's internal and external orientation parameters and the 3D model. The procedures were designed and developed by means of a photogrammetric system, but the greatest development and innovation of these procedures originated from the computer vision from the late $90 \mathrm{~s}$, together with the SfM method. The reconstructions on this method have been useful for visualization purposes and not for photogrammetry and mapping. Thanks to advances in computer technology and computer performance, a large number of images can be automatically oriented in a coordinate system arbitrarily defined by different algorithms, often available in open source software (VisualSFM, Bundler, PMVS2, CMVS, etc.) or in the form of Web services (Microsoft Photosynth, Autodesk 123D Catch, My3DScanner, etc.). However, it is important to obtain an assessment of the accuracy and reliability of these automated procedures. This paper presents the results obtained from the dome low close range photogrammetric surveys and processed with some open source software using the Structure from Motion approach: VisualSfM, OpenDroneMap (ODM) and Regard3D. Photogrammetric surveys have also been processed with the Photoscan commercial software by Agisoft.

For the photogrammetric survey we used the digital camera Canon EOS M3 (24.2 Megapixel, pixel size $3.72 \mathrm{~mm}$ ). We also surveyed the dome with the Faro Focus 3D TLS. Only one scan was carried out, from ground level, at a resolution setting of $1 / 4$ with $3 \mathrm{x}$ quality, corresponding to a resolution of $7 \mathrm{~mm} / 10 \mathrm{~m}$. Both TLS point cloud and Photoscan point cloud were used as a reference to validate the point clouds coming from VisualSFM, OpenDroneMap and Regards3D. The validation was done using the Cloud Compare open source software.
\end{abstract}

\section{INTRODUCTION}

Development of the technology in the field of digital cameras, computer vision and $3 \mathrm{D}$ reconstruction from the images has brought the close range photogrammetry to a high degree of popularity (Jurjević, L. et al., 2017). Furthermore, the implemented automatisms and algorithms in multi-image photogrammetry software both with the low cost of digital cameras have led many architectural operators to approach this methodology.

In particular, thanks to the implementation of the Structure from Motion (SfM) approach also in the software for the close range photogrammetry and drones, low cost software, easy to use and with high performance and accuracy, have been developed.

With these software dense point clouds, high resolution orthophotos and other photogrammetric products can be obtained for accurate and fast documentation of architectural heritage (Grillo et al., 2019, Giannattasio et al., 2013).

This contrasted the multi-image photogrammetry (CRP), based on SfM, to the Terrestrial Laser Scanner (TLS) methodology, the latter, in fact, since it provides fast and comprehensive survey of objects, stable results and visualization of data in the form of digital 3D models.

This contrasted the multi-image photogrammetry (CRP), based on SfM, to the Terrestrial Laser Scanner (TLS) methodology, the latter, in fact, since it provides fast and comprehensive survey of objects, stable results and visualization of data in the form of digital 3D models (Bartoš, K. et al. 2014).

Furthermore, the CRP has many advantages respect to TLS higher accuracy for shorter imaging distances $(<5 \mathrm{~m})$, relatively easy data collection, easy use software, high radiometric resolution of final point cloud and relatively low purchase costs of the photogrammetric system (Fraštia, 2012).

In fact, there are many applications that use multi-image photogrammetry such as the modeling of facades (Fritsch, D., et al. 2013), buildings (Alidoost, F., et al. 2015, Hanan, H., et al. 2015), monuments (Suwardhi, D., et al. 2015, Murtiyoso, A. et al., 2017), etc. Today even the CRP has shown itself able to obtain quality data with high informative value, reliable information about the position of objects, about their geometrical properties and also about radiometric characteristics of their surfaces. Moreover, the development of a considerable number of open source or free software for multi-image photogrammetry that allow $3 \mathrm{D}$ reconstruction from images from digital cameras even at low cost, has further contributed to the spread of multi-image CRP.

The paper presents an overview of some Open Source software for multi-image photogrammetry based on the SfM approach in order to verify the degree of accuracy achievable in the $3 \mathrm{D}$ model reconstruction of an architecture.

The test was done on the dome of the Basilic of the Beata Vergine Assunta in Guasila (Sardinia), chosen for its relevant historical and aesthetical values as well as for the complex 
issues concerning the geometry, the state of conservation of its structures and the painted surfaces that need to be soon restored. The dome was surveyed with a Canon EOS M3 camera and images processed with 3 different Open Source software based on SFM. These are VisualSFM, OpenDroneMap and Regard3D. For the validation of the results, the images have also been processed with the Photoscan commercial software by Agisoft. The dome was also surveyed with the Faro Focus 3D TLS. All point clouds were compared with each other using Open Source Cloud Compare software.

\section{PHOTOGRAMMETRIC OPEN SOURCE SOFTWARE}

\subsection{The current state}

The possibility to obtaining 3D information from images is closely related to the ability to identify the corresponding points of the images that took the same object (Bartoš, K., et al. 2014). In the classical photogrammetry this has always been performed manually by an operator, while with the advent of digital photogrammetry and the development and application of computer vision algorithms, automatic and semi-automatic procedures have been favoured. This approach, called Structure from Motion, has led to an almost completely automatic photogrammetric process.

Indeed, the Structure from Motion allows the generation of 3D data from a series of overlapping images, using the same basic principles of stereoscopic photogrammetry. However, it differs from conventional photogrammetry, since the geometry is reconstructed simultaneously using a highly redundant, iterative bundle adjustment procedure (Szeliski, R., 2010). This process works by automatically identifying correspondence points in multiple images without requiring the specific presence of Ground Control Points (GCPs).

It is important to emphasize that this approach is more suited to sets of images with a high degree of overlap that capture the complete three-dimensional structure of the scene seen from a wide range of positions.

In figure 1 the workflow of 3D model generation of architectural heritage with SFM approch.

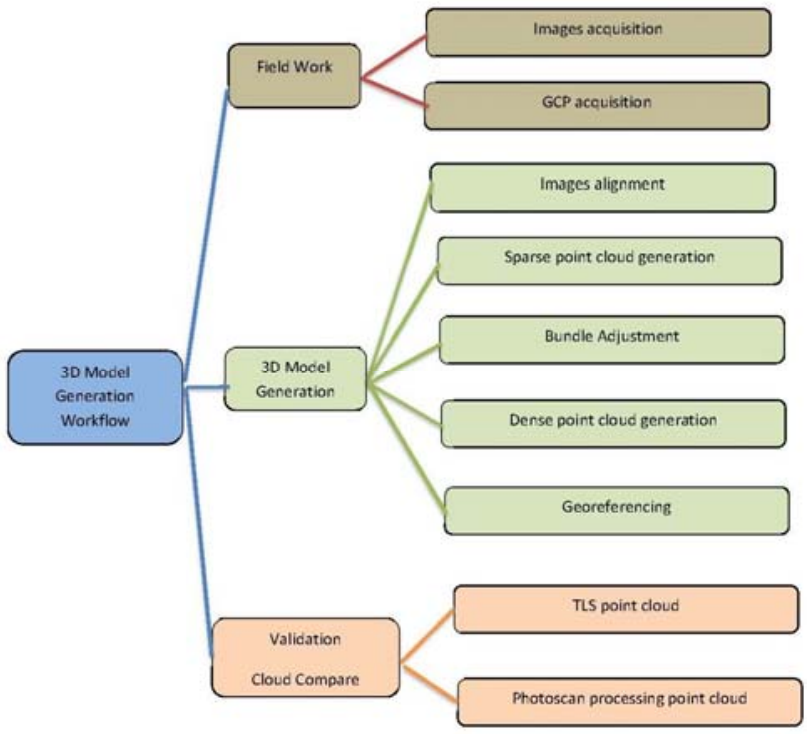

Figure 1: 3D model workflow

In this work 3 open source software have been tested which will be described in the following paragraphs.

\subsection{VisualSFM}

VisualSFM (Fig. 1) is a GUI application for 3D reconstruction of objects from images using the SfM approch. The software developed by Chanchang $\mathrm{Wu}$ in collaboration with the University of Washington and Google, was used for the images alignment by means of the SfM technique (Wu Ch., 2011; Wu Ch., 2007). The dense matching plug-in integrated in its interface, PMVS/CMVS, made by Yasutaka Furukawa, was employed to generate the dense cloud (Furukawa, 2010).

Reconstruction of objects from images using VisualSFM consists of the following steps:

1. open images in the SFM workplace - either through menu or by corresponding panel buttons;

2. run detection of image features and searching correlations between images (matching);

3. run sparse reconstruction - i.e. bundle adjustment and creation of sparse point cloud;

4. georeferencing of point cloud;

4. dense reconstruction using CMVS/PMVS - individual parameters affecting the reconstruction can be find in the nv.ini file that is automatically generated on the first start of software, in its main directory.

The software provides a wide range of settings, by which we can modify the reconstruction process. For example, the change of maximum used resolution of images, with which the SiftGPU algorithm will work; specification of user's own list of image pairs for image matching; direct use of custom list of image features; use of custom feature detectors instead of SiftGPU; and more.
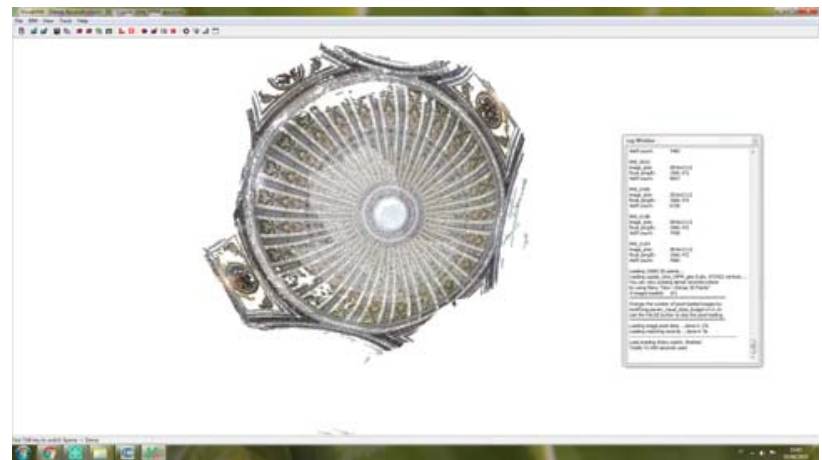

Figure 2: VisualSfM Software

\subsection{WebODM WebOpenDroneMap}

WebOpenDroneMap (WebODM) is an open source toolkit for processing aerial drone imagery, but in this case, we used WebODM for the close range photogrammetry. Typical drones use simple point-and-shoot cameras, so the images from drones, while from a different perspective, are similar to any pictures taken from point-and-shoot cameras, i.e. non-metric imagery. OpenDroneMap turns those simple images into threedimensional geographic data that can be used in combination with other geographic datasets.

In a word, OpenDroneMap is a toolchain for processing raw civilian UAS imagery to other useful products. The ODM software makes the next products:

1. Point Clouds;

2. Digital Surface Models;

3. Textured Digital Surface Models;

4. Orthorectified Imagery;

5. Classified Point Clouds; 


\section{Digital Elevation Models.}

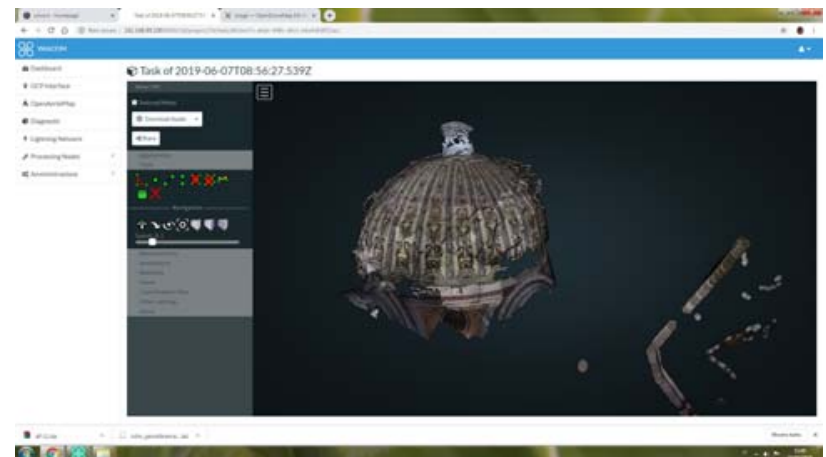

Figure 3: ODM Software

\subsection{Regard3D}

Regard3D is a SfM software that can create 3D models from objects using a series of images taken of this object from different viewpoints.

To obtain a 3D model, the following steps are performed:

- for each image, features are detected. Features are points in an object that have a high probability to be found in different images of the same object. For each feature, a mathematical descriptor is calculated.

- The descriptors from different images are matched and geometrically filtered. The result of this step is a collection of matches between each image pair.

- For each feature that is part of a match in an image pair, it is searched also in other images. A track is generated from features if these features satisfy some conditions, for example a track is seen in at least 3 images.

- The next step is the triangulation phase. All the matches of all the image pairs are used to calculate:

0 The 3D position and characteristic of the "camera", i.e. where each image was shot and the visual characteristics of the camera

o The 3D position of each "track" is calculated

- The result of the triangulation phase is a sparse point cloud. In order to obtain a more dense point cloud ("densification"), several algorithms can be used.

- The last step is called "Surface generation". The point clouds are used to generate a surface, either with colored vertices or with a texture.

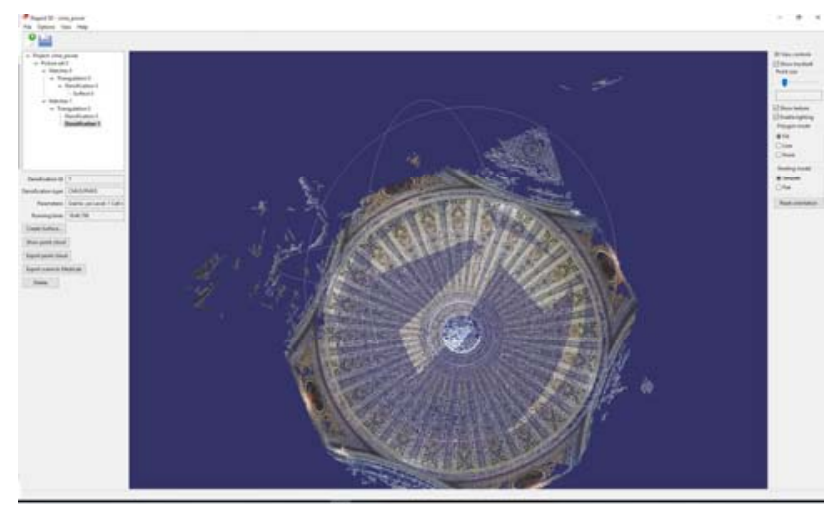

Figure 4: Regard3D

\section{THE TEST}

\subsection{The dome of the Beata Vergine Assunta Basilic}

The photogrammetric survey and all images processing with the OS software were performed for the 3D model of the dome of the Basilica of the Beata Vergine Assunta.

The Basilic, designed in 1839 by one of the most important architects in the ninetieth Sardinia context, Gaetano Cima, and officially open to the cult in the 1852, was built in partial overlapping on an older ruined Baroque church demolished for its state of obsolescence (Virdis et al., 2003). It is a 'temple' with a central plan, considered as first example of neoclassic architecture on the local panorama of religious architectures. The church is preceded by a pronao constituted by six Doric columns and two lateral pillars, that support a triangular tympanum with the inscription of the monument to the Vergine Assunta. The central body, wide 28 metres of diameter, is covered by an ample dome with a lantern based on four massive pillars each of which is placed side by side by two elegant Doric columns opening to six lateral chapels.

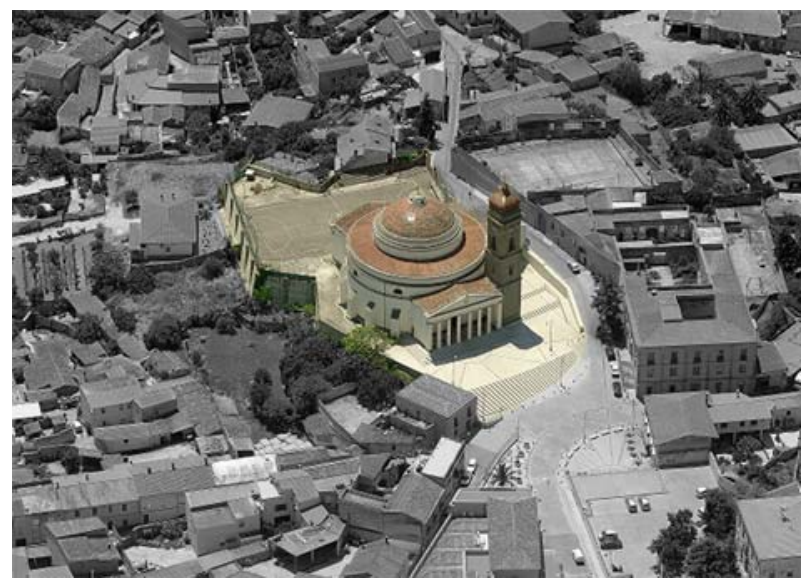

Figure 5:Aerial view of the Basilic

An element of significant value is the dome of this basilic, clearly inspired by the Pantheon in Roma, in this period example of innovation and classicism for all the religious architecture in Europe. The hemispheric structure, based on a tambour, is wide 16 metres and it is closed by a lantern replaced probably in 30 s during restoration works. The structure is built in two different materials: local sandstone for one third of the hemisphere and the rest in bricks according to the coeval building techniques. Internally, the dome is completely painted with 24 sectors constituted by geometric and floral elements designed by the same architect plainly influenced by the neoclassic style in terms of details and colours. Unfortunately, the poor ability of the builders and their scarce skills on similar structures drove towards several static problems, increased by the low quality of building materials. In 1978, the high level of rain infiltrations caused the detachment of around the $15 \%$ of the total surface of painted plasters (400 mq), whereas the rest was characterised by several cracks. For that reason, a specific restoration work, financed by the Superintendence, was realised repainting all the internal dome but leaving unsolved the real issues of its ongoing decay. 


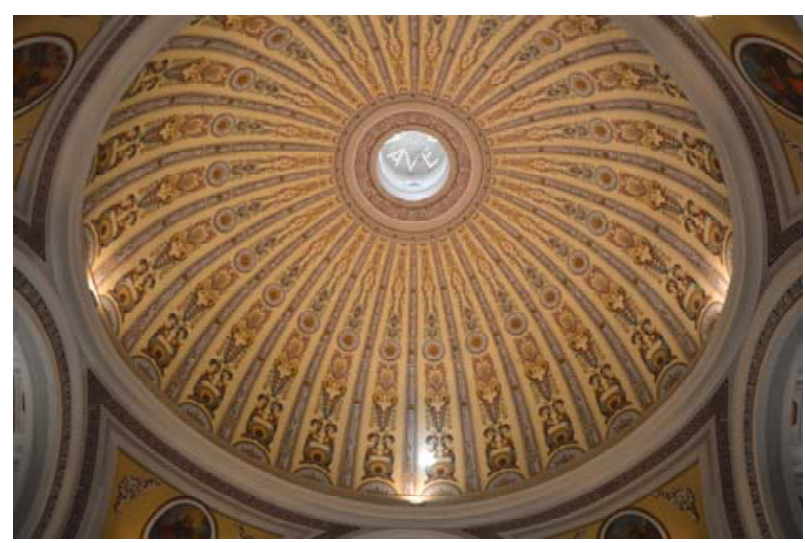

Figure 6: The dome

\subsection{Methodology}

The survey dome was done both with a low cost Close Range Photogrammetry (CRP) system and with a Terrestrial Laser Scanning technique (TLS).

The aim was to verify the level of accuracy possible reachable with the low cost CRP system and the software tested: VisaulSfM, WebODM and Regard3D.

The low-cost Close Range Photogrammetric (CRP) system included a digital camera Canon EOS M3 with a sensor CMOS $22.3 \times 14.9 \mathrm{~mm}$ and a 24.2 Megapixel resolution; objective EF-S 18-55 mm; the output data formats are Exif 2.3 (JPEG) and RAW (CR2 Canon original). The photogrammetric survey with the EOS M3 was performed using a mobile platform, with distances between the camera position and the dome varying between 3 and $8 \mathrm{~m} .97$ images have been acquired by the EOS M3 and processed with different software open source on an HP Z420 workstation with 64 GB RAM, Intel Xeon E5-16200 3.60 $\mathrm{GHz}$ CPU, and NVIDIA Quadro K2000 video card.

The images were processed also with the software Photoscan Agisoft, the commercial photogrammetric software widely used and tested. The processing was done with high resolution and the point cloud obtained had 114.453 .295 points.

The dome was also surveyed with the Faro Focus 3D TLS. Only one scan was carried out, from ground level, at a resolution setting of $1 / 4$ with $3 x$ quality, corresponding to a resolution of $7 \mathrm{~mm} / 10 \mathrm{~m}$. In this way a point cloud with 9.309.845 points was obtained.

In the table 1 there are the parameters used with the different software open source.

\begin{tabular}{|c|c|c|c|}
\hline & images & n. points & Time \\
\hline VSFM & 101 & 696.736 & $2 \mathrm{~h}$ \\
\hline Regard 3D & 101 & 701.259 & $4 \mathrm{~h}$ \\
\hline WebODM & 101 & 3.545 .806 & $3 \mathrm{~h}$ \\
\hline
\end{tabular}

Table 1: Surveys data

All the images were processing with the default parameters OS software and georeferenced using at least 5 GCP and the rms for all the surveys have been around 3-4 cm. The figures 7, 8, 9, 10 and 11 show the point clouds with VisualSfM, ODM, Regard3D, Photoscan softwares and TLS.

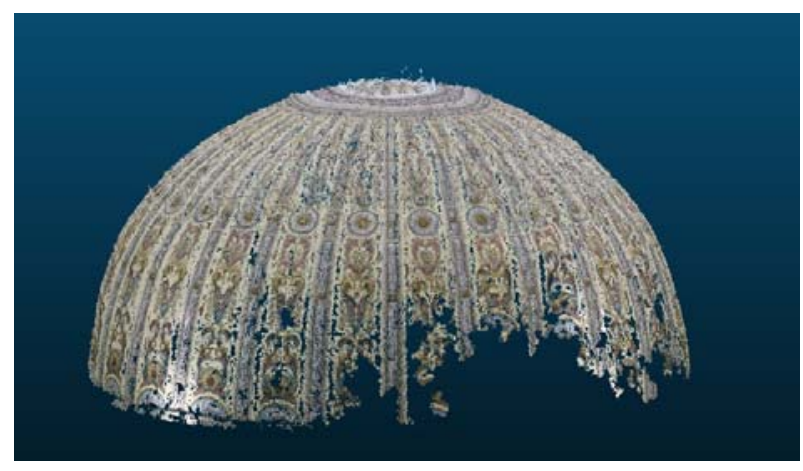

Figure 7: VisualSFM dense point cloud

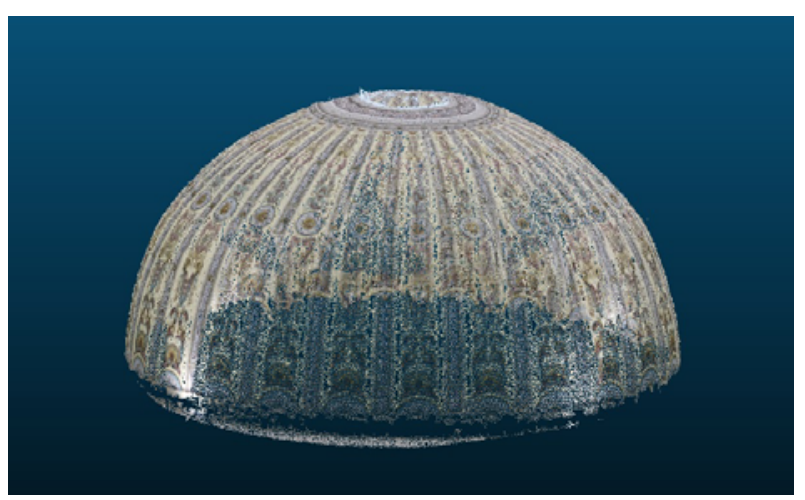

Figure 8: Regard 3D dense point cloud

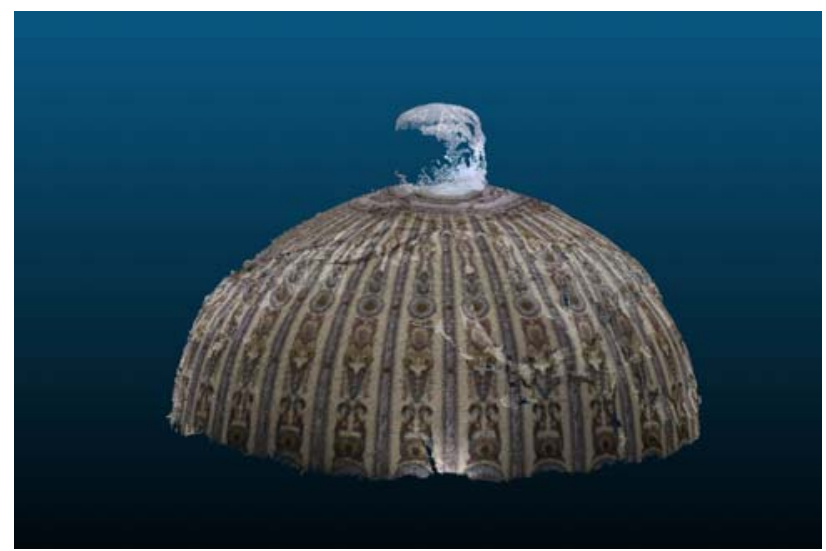

Figure 9:ODM dense point cloud 


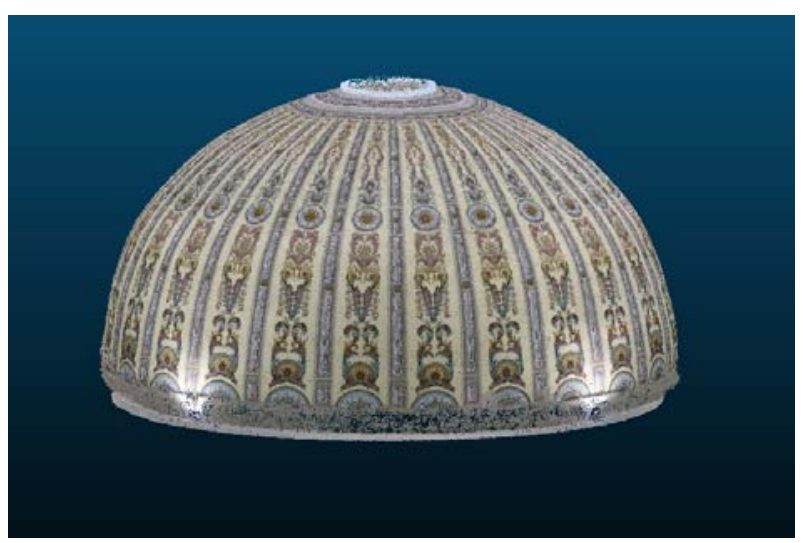

Figure 10: Photoscan dense point cloud

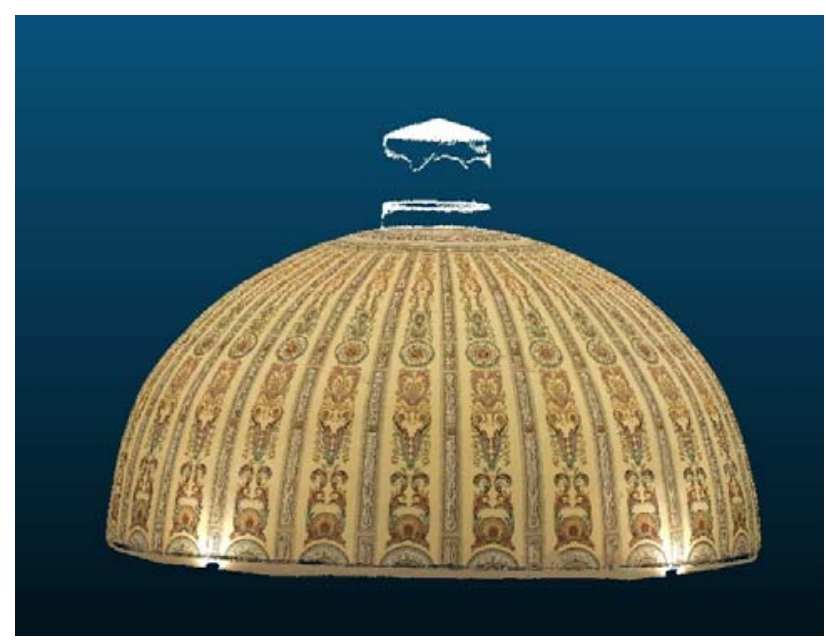

Figure 11: TLS point cloud

\section{RESULTS}

The CRP dense point clouds from OS software have been compared with point cloud from Photoscan software and from the TLS survey. This comparison was done both comparing the measurements of distances taken on the point clouds obtained from different CRP surveys and different software and TLS surveys, and comparing the point clouds themselves using the CloudCompare software (Open Source Software). Specifically, this analysis was done by calculating the minimal distance between every point of the models using the nearest neighbour algorithm. Furthermore, the software allows the calculation of statistical values, such as the minimal distance, maximal distance, average distance, and standard deviation.

Table 2 reports the results of the comparisons between the point clouds obtained with TLS and the point clouds from Photoscan. Table 3 instead, reports the results of the comparisons between the point clouds obtained with TLS and the point clouds from VisualSfM, ODM and Regard 3D.

\begin{tabular}{|c|c|}
\hline Software & Photoscan \\
\hline Min $(\mathrm{m})$ & 0 \\
\hline Max $(\mathrm{m})$ & 0.718 \\
\hline Mean $(\mathrm{m})$ & 0.032 \\
\hline Dev. Stand $(\mathrm{m})$ & 0.066 \\
\hline
\end{tabular}

Table 2: Statistical values of the comparisons between the TLS data and the Photoscan point clouds.

\begin{tabular}{|c|c|c|c|}
\hline Software & VSFM & ODM & Regard3D \\
\hline Min $(\mathrm{m})$ & 0 & 0 & 0 \\
\hline Max $(\mathrm{m})$ & 1.06 & 0.84 & 0.68 \\
\hline Mean $(\mathrm{m})$ & 0.01 & 0.17 & 0.00 \\
\hline Dev. Stand (m) & 0.04 & 0.16 & 0.03 \\
\hline
\end{tabular}

Table 3: Statistical values of the comparisons between the TLS data and the VisualSfM, ODM and Regard 3D point clouds
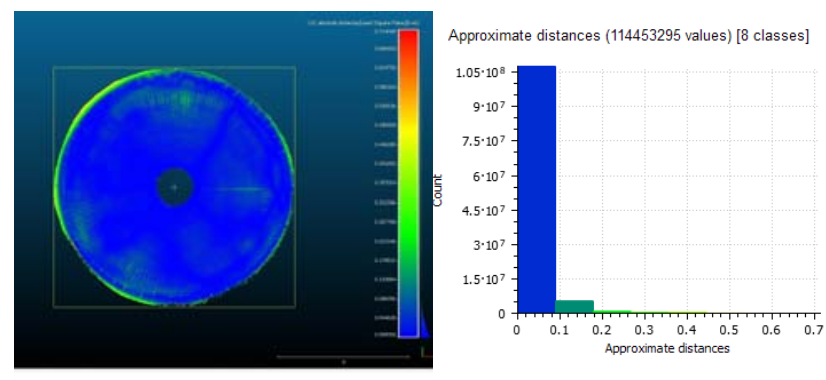

Figure 12: Discrepancy (m) map and histogram between the TLS point cloud and Photoscan processing.
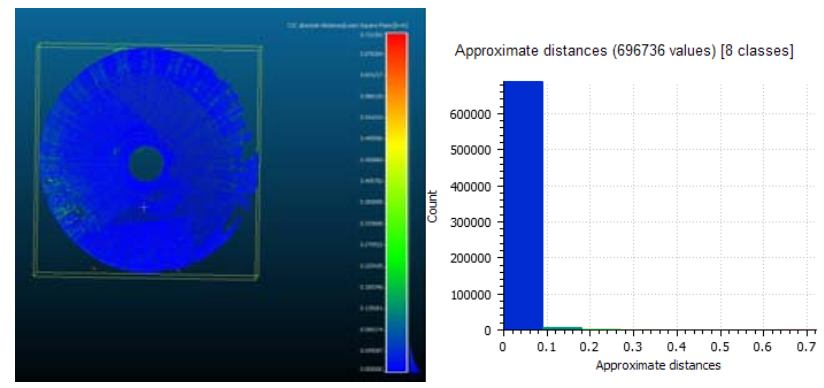

Figure 13: Discrepancy (m) map and histogram between the TLS point cloud and VisualSfM processing.
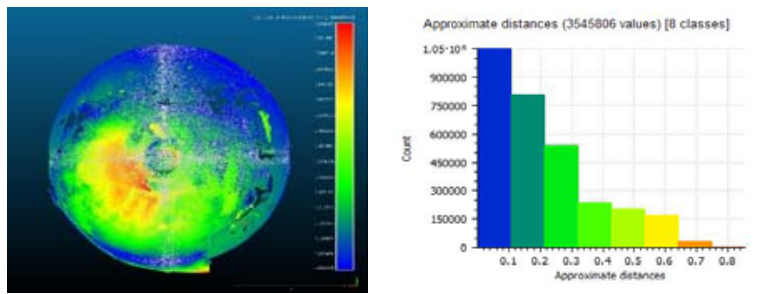

Figure 14: Discrepancy (m) map and histogram between the TLS point cloud and ODM processing.
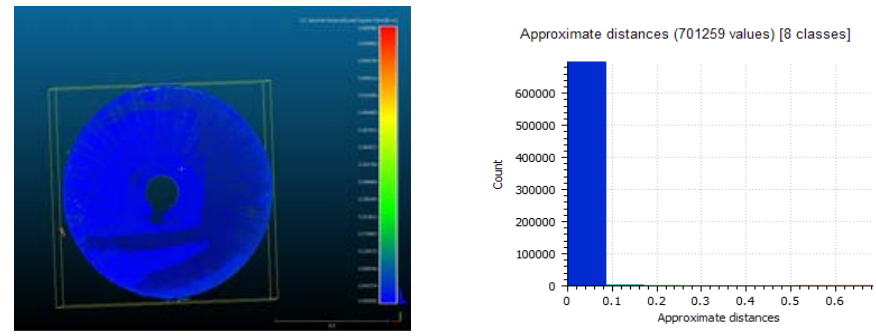

Figure 15: Discrepancy (m) map and histogram between the TLS point cloud and Regard 3D processing. 


\section{DISCUSSION AND CONCLUSIONS}

The paper describes the test about a 3 different software Open Source for the photogrammetry multi-images: VisualSfm, OpenDroneMap and Regard3D. In particular we wanted to test the accuracy and functionality of this OS software and compare it to those already extensively tested by Photoscan, as well as to the 3D model coming from a TLS survey.

The use of VisualSfM was easy and immediate, with faster processing times especially compared to those of Photoscan. One problem encountered was the georeferencing, which was a long and not very automated process.

As shown in figure 7, however, despite having a few centimeters of accuracy, the dome was not completely reconstructed with respect to Photoscan.

Even Regard3d software is easy and immediate to use, the accuracy achieved is good. The number of points in the cloud is not very high and even its reconstruction is not complete (figure 8). ODM presented some problems in the processing that was done only with the Default procedure, even the accuracy is higher than the other two software. The number of points is much higher. The tests will carry on by also testing the other processing methods. The software is very easy to use, and the calculation process is completely automatic.

These first results obtained can be considered reassuring since the chosen architecture had a difficult geometry and the painting, with repetitive decorative elements, can create problems for the recognition of the points.

The research carries on by continuing to test the software in their different potentials and in their processing methods. The final and complete results will be published shortly.

\section{ACKNOWLEDGEMENTS}

This study was also supported by the project "Healthy Cities and Smart Territories", founded by the Foundation of Sardinia and Autonomous Region of Sardinia (Fondazione di Sardegna Convenzione triennale tra la Fondazione di Sardegna e gli Atenei Sardi Regione Sardegna 2016)

\section{REFERENCES}

Alidoost, F.; Arefi, H. 2015. An image-based technique for 3D building reconstruction using multi-view UAV images. Int. Arch. Photogramm. Remote Sens. Spat. Inf. Sci. 2015; XL1/W5, 43-46.

Bartoš, K.; Pukanská, K.; Sabová, J.; 2014. Overview of available opensource photogrammetric software, its use and analysis. International. Journal for Innovation Education and Research 2(4): 62-70.

Battini, C.; Vecchiattini, R.; 2017. Survey and restoration: New ways of interaction. Int. Arch. Photogramm. Remote Sens. Spat. Inf. Sci. 2017, 42-5/W1, 655-662.

Deidda, M.; Musa, C.; Vacca, G.; 2015. A GIS of Sardinia's Coastal defense system (XVI-XVIII century). Int. Arch. Photogramm. Remote Sens. Spat. Inf. Sci. 2015, 40-4/W7, 1722.

Fraštia, M.; 2009. Fotogrametria v procese dokumentácie pamiatok. Bardkontakt. Problematika mestských pamiatkových centier. Bardejov, Mesto Bardejov, ISBN 978-80-970188-9-4, s. 30-35.

Furukawa, Y., Ponce, J., 2010. Accurate, dense, and robust mul-tiview stereopsis. IEEE transactions on pattern analysis and machine intelligence, 32(8), pp. 1362-1376.

Fritsch, D.; Becker, S.; Rothermel, M.; 2013. Modeling Façade Structures Using Point Clouds from Dense Image Matching. In Proceedings of the International Conference on Advances in Civil, Structural and Mechanical Engineering, Hong Kong, China, 3-4 August 2013; pp. 57-64.

Grillo, S. M.; Pilia, E.; Vacca, G.; 2019.Integrated study of the Beata Vergine Assunta dome with Structure from Motion and diagnostic approaches. Int. Arch. Photogramm. Remote Sens. Spat. Inf. Sci. 2019, 42-2/W11, 579-585.

Giannattasio, C.; Grillo, S.M.; Vacca, G.; 2013. Interdisciplinary study for knowledge and dating of the San Francesco Convent in Stampace, Cagliari - Italy (XIII-XXI Century), ISPRS Ann. Photogramm. Remote Sens. Spatial Inf. Sci., II-5/W1, 139-144, doi:10.5194/isprsannals-II-5-W1-1392013, eISSN 2194-9050

Hanan, H.; Suwardhi, D.; Nurhasanah, T.; Bukit, E.S. Batak Toba. 2015. Cultural Heritage and Close-range Photogrammetry. Procedia Soc. Behav. Sci. 2015, 184, 187195.

Jurjević, L., and Gašparović, M., 2017. "3D Data Acquisition Based on OpenCV for Close-range Photogrammetry Applications", The International Archives of Photogrammetry, Remote Sensing and Spatial Information Sciences, 42, 377.

Murtiyoso, A.; Grussenmeyer, P.; 2017. Documentation of heritage buildings using close-range UAV images: Dense matching issues, comparison and case studies. Photogramm. Rec. 2017, 32, 206-229

Suwardhi, D.; Menna, F.; Remondino, F.; Hanke, K.; Akmalia, R. 2015. Digital 3D Borobudur-Integration of 3D Surveying and Modeling Techniques. Int. Arch. Photogramm. Remote Sens. Spat. Inf. Sci. 2015, XL-5/W7, 417-423.

Szeliski, R., 2010. Computer vision: algorithms and applications. Springer.

Vacca, G.; Dessì, A.; Sacco, A., 2017. The Use of Nadir and Oblique UAV Images for Building Knowledge. ISPRS Int. J. Geo-Inf., 6, 393.

Vacca, G.; Mistretta, F.; Stochino, F.; Dessi, A., 2016. Terrestrial laser scanner for monitoring the deformations and the damages of buildings. In Proceedings of the International Archives of Photogrammetry, Remote Sensing and Spatial Information Sciences, pp. 453-460.

Virdis, F., Puddu, T. 2003. Gaetano Cima. Il tempio della villa di Guasila, documenti di archivio.

Westoby, M.J.; Brasington, J.; Glasser N.F.; Hambrey, M.J.; Reynolds, J.M., $2012 . \quad$ 'Structure-from-Motion' photogrammetry: a low-cost, effective tool for geoscience applications. Geomorphology, 179, pp. 300-314. 
Wu, C., 2011. VisualSFM: A visual structure from motion system. http://ccwu.me/vsfm

Wu, C., 2007. SiftGPU: A GPU implementation of scale invariant feature transform (SIFT)

https://docs.opendronemap.org/index.html

http://www.regard3d.org/index.php/documentation/introduction 